\title{
INSTITUCIONES SOCIALES MODERNAS
}

\section{LA CONFEDERACION NACIONAL DE LOS CULTIVADORES DIRECTOS DE ITALIA}

Esta Confederación se fundó en 1944. El 31 de diciembre de dicho año ya contaba con 349 secciones, convertidas en 9.876 al cabo de diez años, subiendo las familias socias de 71.000 a 1.100 .000 . Actualmente la Confederación cuenta con 14.290 secciones periféricas en municipios o fracciones de municipio con 1.700.000 familias asociadas, a las que corresponden 3.500 .000 unidades laborales y casi 8.000 .000 unidades representadas.

La Confederación está estructurada en federaciones provinciales y secciones laborales; están asociadas a ella la Federación nacional de los pequeños propietarios de la reforma agraria, la Federación nacional de los colonos y aparceros y la Federación Nacional de Pastores. Siendo organización de familias, tiene en su seno los Grupos Juveniles Cultivadores presentes en casi 8.000 secciones y los grupos de Mujeres Rurales con más de 8.300 secciones. Los Grupos de Jóvenes Cultivadores hace algunos años han dado vida a la Federación Italiana de los Clubs 3P que organiza más de 2.000 clubs masculinos y femeninos para la divulgación de la técnica agrícola. Forman parte además de la Confederación dos organismos con funciones particulares: el Ente de Patrocinio y de Asistencia a los Cultivadores Agrícolas y el Instituto Nacional para la Instrucción profesional en la Agricultura.

La Confederación es un sindicato y presenta características comunes a todos los sindicatos y además tiene algunas propias. Las más importantes son : la inspiración social cristiana y la democracia en su estructura y en su método.

En sus líneas esenciales su acción tiende a realizar los siguientes principios:

La prioridad de la persona humana y de sus derechos fundamentales respecto sobre todo del Estado: la organización social ha de servir al hombre, y no el hombre ha de ser esclavo del Estado; la producción, la economía, la 
M. B.

política han de tener en cuenta los derechos naturales del hombre y su inmedita proyección social, la familia.

La propiedad privada - como manifestación de un derecho natural del hombre para mejorar sus condiciones- es un derecho de naturaleza que no puede ser suprimido por nadie; rás aún, puesto que la propiedad aumenta la capacidad operativa del hombre, constituye una aspiración fundamental suya y ayuda a su más amplia autonomía en el campo económico.

El Estado tiene el deber de ayudar al individuo, actuar sus aspiraciones y realizar sus derechos fundamentales; a tal fin ha de intervenir para remediar los desequilibrios sociales y económicos que periódicamente se realizan en la sociedad.

Por lo que toca al método de acción sindical, la Confederación cree en la eficacia del sindicalismo democrático. Rechazando el método de la violencia maximalista, está por una progresiva reforma de las estructuras, por una continua y rápida evolución que permita al mundo campesino alcanzar la partidad con las otras categorias. Sobre todo rechaza como improductiva, irracional y anticristiana la revolución y la lucha de clase y reconoce como las más inmediatas consecuencias de una concepción cristiana y democrática de la vida social: la prioridad del trabajo sobre el capital; conviene por tanto favorecer la propiedad campesina como la que mejor responde al progreso económico y humano de los cultivadores; el reconocimiento de que la empresa campesina constitnye un instrumento de trabajo y no un capital; el derecho de los cultivadores a una efectiva paridad económica y social con las otras categorias; el derecho de los cultivadores a participar efectivamente en el gobierno del propio mundo y a colaborar en el enderazamiento de la vida social en sus varias formas.

La verdadera estabilidad social es fruto de un equilibrio entre las categorias y los sectores productivos, de modo que ésta encuentra su base en un reconocimiento de los derechos y de las justas aspiraciones de los cultivadores y en la realización de las condiciones que les permitan asumir la dirección de las cosas propias, entrando cada vez más como elemento activo a colaborar en esta compaginación social que es el Estado.

Según estas orientaciones, las principales conquistas obtenidas por la Confederación han sido las siguientes: Asistencia de Enfermedad (ley de 1954) con contribución a cargo del Estado de la mitad de los gastos; Pensión de Invalidez y de Vejez (ley de 1957) con contribución del Estado para la constitución del fondo de pensiones; defensa del precio de los productos a través de «stocks» contingentes y voluntarios con contribuciones del Estado sobre los gastos de gestión. Las provisiones han afectado a los siguientes productos: grano, maiz, olivo, arroz, vino, mantequilla, queso, cáñamo, etc; tutela y mejora del patrimonio zootécnico con la adopción de precios mínimos para la defensa de los precios, con facilidades crediticias para la adquisición de ganado selecto, saneamiento zootécnico y mejora de las plantas y de los medios 
técricos; politica tendente a disminuir los costes de los medios técnicos, en particular máquinas agrícolas y abonos y a dîndir su empleo, con contribuciones particulares para la adquisición de semillas selectas; desgravaciones fiscales varias; Plan quinquenal de desarollo (ley 1961) llamado «Plan Verde»; gradual inserción de los campesinos en los puestos de responsabilidad y entre las clases dirigentes de la sociedad; cerca de 40.000 cultivadores son administradores municipales; las Cajas Mutuas de los Cultivadores Directos Comunales y Provinciales son llevadas por auténticos cultivadores; los consorcios agrarios, las cooperativas agrícolas y los entes económicos varios que interesan a la agricultura son administrados por los campesinos; la presencia cada vez más masiva y responsable en la vida polútica y administrativa; la constitución de un grupo parlarnentario de representantes de los cultivadores, compuesto en gran parte de cultivadores y de un grupo senatorial de «amigos de los cultivadores».

Las próximas metas de la Confederación se indican en las peticiones presentadas a la Conferencia Nacional del Mundo Rural y de la Agricultura. Se pueden así resumir:

Completar la asistencia social con la concesión de los subsidios familiares a los cultivadores, colonos y aparceros para los hijos hasta los 14 años; préstamos de 30 años con el 1 por 100 de interés para la formación de nuevas propiedades familiares; ulteriores reducciones de exenciones fiscales y contributivas, en particular: reducción del 50 por 100 en las contribuciones sobre la mutua y las pensiones; reducción del 50 por 100 en las contribuciones unificadas más allá de las 30.000 liras; exención del pago de impuestos sobre los terrenos, con rentas inferiores a 240.000 liras; exención del pago de los impuestos para la propiedad campesina, sólo para los pequeños propięarios; fondo de 50 mil millones para la estabilización de los precios agrícolas y para evitar crisis improvisadas de mercado; construcción, con contribuciom nes del Estado, de cantinas, fábricas de queso, almazaras, centrales horôfructicolas y otras plantas aptas para el sostén de los precios agrícolas; reducción de la tasa sobre el crédito agrario para permitir rebajar los costes de producción mecanizando la hacienda; mayor disponibilidad de fondos para el «Plan Verde».

La Confederación se propone: favorecer la creación y el desarrollo de la propiedad-directa-cultivadora, en todos sus aspectos sociales y productivos, promoviendo también una legislación idónea para tutelar sus intereses respecto de los caracteres particulares y exigencias de la categoría; asistir a los enfiteutas y categorías afines en la salvaguardia de sus derechos y en la consecución de la plena propiedad de la tierra; asegurar a los arrendatarios cultivadores directos una favorable posición contractual que les garantice la máxima posible estabilidad en la finca y una renta adecuada a su aportación fundamental de trabajo y de capital; asistir a los pequeños propietarios de la Reforma en sus relaciones con los entes que conceden la 
M. B.

propiedad; atender a la defensa de sus intereses de operadores agrícolas autónomos; tutelar los intereses de los aparceros y colonos, aun mediante una disciplina de las relaciones contractuales que, reafirmando los derechos del trabajo y valorizando la personalidad humana, garantice a las categorías un tenor de vida cada vez mejor y la seguridad social; promover toda forma de tutela social a favor de las categorías representadas; promover y procurar la extensión y la mejora de la Instrucción Profesional.

M. B. 